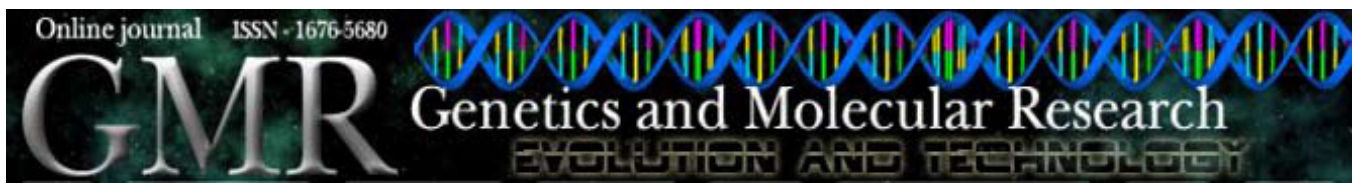

\title{
Polymorphisms and DNA methylation of gene TP53 associated with extra-axial brain tumors
}

\author{
L.O. Almeida ${ }^{1}$, A.C. Custódio ${ }^{1}$, G.R. Pinto ${ }^{1,3}$, M.J. Santos ${ }^{2}$, \\ J.R.W. Almeida ${ }^{2}$, C.A. Clara ${ }^{2}$, J.A. Rey ${ }^{4}$ and C. Casartelli ${ }^{1}$ \\ ${ }^{1}$ Departamento de Genética, Faculdade de Medicina de Ribeirão Preto, \\ Laboratório de Oncogenética, Universidade de São Paulo, \\ Ribeirão Preto, SP, Brasil \\ ${ }^{2}$ Fundação Pio XII, Hospital de Câncer de Barretos, Barretos, SP, Brasil \\ ${ }^{3}$ Laboratório de Genética Humana e Biologia Molecular, \\ Universidade Federal do Piauí, Parnaíba, PI, Brasil \\ ${ }^{4}$ Departamento de Cirurgia Experimental, \\ Laboratótio de Oncogenética Molecular, \\ Hospital Universitário “La Paz”, Madrid, Espanha
}

Corresponding author: L.O. Almeida

E-mail: lu_olive@yahoo.com

Genet. Mol. Res. 8 (1): 8-18 (2009)

Received October 29, 2008

Accepted November 21, 2008

Published January 6, 2008

\begin{abstract}
The p53 tumor suppressor gene is the most frequently mutated gene in human cancer; this gene is mutated in up to $50 \%$ of human tumors. It has a critical role in the cell cycle, apoptosis and cell senescence, and it participates in many crucial physiological and pathological processes. Polymorphisms of p53 have been suggested to be associated with genetically determined susceptibility in various types of cancer. Another process involved with the
\end{abstract}


development and progression of tumors is DNA hypermethylation. Aberrant methylation of the promoter is an alternative epigenetic change in genetic mechanisms, leading to tumor suppressor gene inactivation. In the present study, we examined the TP53 Arg72Pro and Pro47Ser polymorphisms using PCR-RFLP and the pattern of methylation of the p53 gene by methylation-specific PCR in 90 extra-axial brain tumor samples. Patients who had the allele Pro of the TP53 Arg72Pro polymorphism had an increased risk of tumor development (odds ratio, $\mathrm{OR}=3.23$; confidence interval at $95 \%, 95 \% \mathrm{CI}=1.71-6.08 ; \mathrm{P}=0.003)$, as did the allele Ser of TP53 Pro47Ser polymorphism $(\mathrm{OR}=1.28 ; 95 \% \mathrm{CI}=0.03-2.10 ; \mathrm{P}=0.01)$. Comparison of overall survival of patients did not show significant differences. In the analysis of DNA methylation, we observed that $37.5 \%$ of meningiomas, $30 \%$ of schwannomas and $52.6 \%$ of metastases were hypermethylated, suggesting that methylation is important for tumor progression. We suggest that TP53 Pro47Ser and Arg72Pro polymorphisms and DNA hypermethylation are involved in susceptibility for developing extra-axial brain tumors.

Key words: Polymorphism; Methylation; TP53; Metastases; Meningiomas; Schwannomas

\section{INTRODUCTION}

Extra-axial tumors are tumors of extracerebral location. They are usually benign. The location of brain tumors affects treatment planning and predicts their prognosis. Meningiomas are the most common extra-axial neoplasms and the second most common primary tumors of the central nervous system, accounting for 13 to $26 \%$ of neoplasms (Liu et al., 2005). Other common extra-axial neoplasms are schwannomas and metastatic lesions. Schwannomas are benign tumors and are the second most common extra-axial intracranial neoplasms, constituting 5 to $10 \%$ of all intracranial neoplasms. The most frequent brain metastases are located in the supratentorial compartment (calvarial, dural or leptomeningeal); about 100,000 people die every year with brain metastases (Drevelegas, 2005).

The human tumor suppressor gene TP53 encodes a transcription factor at the center of a network that maintains cellular integrity by the inhibition of cell growth and stimulation of apoptosis in response to cellular stresses such as DNA damage. Without an intact p53 pathway, damaged cells continue to proliferate, accumulating more and more genetic lesions that can eventually lead to cancer. Over 20,000 alterations in TP53 have been discovered in human tumors, and the role of TP53 in cancer is one of the most extensively studied (Hurt et al., 2006; Sprague et al., 2007).

Predisposition to several human cancers has been associated with genetic polymorphisms, which may represent an important contribution to cancer susceptibility and tumor behavior. Several polymorphisms have been identified within the TP53 gene, both in non-coding and coding regions (Costa et al., 2008). Most of these polymorphisms are single-nucleotide polymorphisms (SNPs) affecting a single base. In TP53 gene, a great number of these natural 
variants are located in introns. Among the polymorphisms found in the coding regions, only two alter the amino acid sequence of their products (Pietsch et al., 2006).

The gene TP53 has a common SNP that results in either arginine (CGC) or proline (CCC) at codon 72 in exon 4 . The polymorphism occurs in the proline-rich domain of the p53 protein, which is necessary for the protein to fully induce apoptosis (Zhu et al., 2007). The functional difference between the 2 alleles of this polymorphism is that the Arg/Arg genotype induces apoptosis with faster kinetics and suppresses transformation more efficiently than the Pro/Pro genotype (Kuroda et al., 2007). At least part of the increased apoptotic potential of the Arg allele is due to the enhanced mitochondrial localization of this protein, where it was found that p53 can interact directly with the pro-apoptotic protein BAK. Several reports indicate that the Pro allele, with lower apoptotic activity, is associated with increased risk of many cancers (Leu et al., 2004; Li et al., 2005).

Another polymorphism site of TP53, at codon 47 of the same exon 4, was also demonstrated to significantly decrease p53 ability to induce apoptosis. Codon 47 encodes proline (CCG) in wild-type p53, but in a small subset of individuals it can encode serine (TCG). The serine 47 polymorphic variant, which replaces the proline residue necessary for recognition by proline-directed kinases, is a markedly poorer substrate for phosphorylation (Leite et al., 2006).

Cancer has been shown to involve global hypomethylation with a very specific hypermethylation of a subset of genes. Aberrant methylation of the promoter represents an alternative epigenetic change to the genetic mechanisms, leading to tumor suppressor gene inactivation. Methylation of specific subsets of $\mathrm{CpG}$ islands has been proposed to be associated with specific tumor types (Esteller et al., 2001; Bello et al., 2004). Hypermethylation of promoters usually occurs at $\mathrm{CpG}$ islands. The promoter of $\mathrm{p} 53$ does not contain $\mathrm{CpG}$ islands; it has been shown that a minimal promoter of $85 \mathrm{bp}$ that contains $16 \mathrm{CpG}$ dinucleotides occurs in the beginning of this gene and is required for full activity. Furthermore, this region has been shown to be methylated in several cancers (Hurt et al., 2006).

In the present research, a case-control study was conducted to examine the genotype distribution of TP53 Pro47Ser and Arg72Pro SNPs and to search for an association between extra-axial brain tumors and TP53 SNPs, using the polymerase chain reaction-restriction fragment length polymorphism (PCR-RFLP) approach. Using methylation-specific PCR (MSPCR) and sequencing, we also evaluated the promoter hypermethylation profile of the TP53 gene in extra-axial brain tumors.

\section{MATERIAL AND METHODS}

\section{Study population}

Ninety extra-axial brain tumors were analyzed, which had been surgically resected from previously untreated patients under the care of the Neurosurgery Department of Fundação Pio XII, Cancer Hospital of Barretos (Barretos, SP, Brazil). The samples, classified according to WHO criteria, were: 48 meningiomas, 23 schwannomas and 19 metastases. The clinical outcome, including length of survival, was obtained from patient records and by contacting each patient's general practioner. For SNP studies, blood samples of 100 healthy individuals were collected as control. Because of the highly heterogeneous ethnic composition of the Brazilian population, the individuals of the control group were selected from the general population of São Paulo State, with no family history of cancer in first-degree rela- 
tives. For the promoter hypermethylation studies, two non-neoplastic brain tissue samples were studied as control.

\section{DNA extraction and primer construction}

DNA extraction was performed using proteinase $\mathrm{K}$ and phenol-chloroform according to routine molecular biology protocols. Primers were constructed using the Gene Runner 3.05 program (Hasting Software, Inc.) from gene sequence of the TP53 Pro47Ser and Arg72Pro polymorphism, obtained in the dbSNP of NCBI (accession numbers: rs1800371 and rs 1042522, respectively). Specific primers for $\mathrm{CpG}$ islands located near the promoter region of the TP53 gene were constructed using the MethPrimer program (Li and Dahiya, 2002) for the MS-PCR analysis. Table 1 shows the primers and PCR product sizes.

\begin{tabular}{lclcc}
\multicolumn{2}{l}{ Table 1. Polymerase chain reaction primers. } \\
\hline & Primer & Sequence & Length (bp) & PCR product (bp) \\
\hline SNP TP53 Arg72Pro & Arg72Pro-F & GAA GAC CCA GGT CCA GAT GA & 20 & 152 \\
& Arg72Pro-R & CTG CCC TGG TAG GTT TTC TG & 20 & \\
SNP TP53 Pro47Ser & Pro47Ser-F & CTG GTA AGG ACA AGG GTT GG & 20 & $201 / 185$ \\
& Pro47Ser-R & TCA TCT GGA CCT GGG TCT TC & 20 & \multirow{2}{*}{166} \\
MS-PCR p53 gene & P53 M-F & CGT CGT ATT TCG GAT TAG ATT TC & 23 & 23 \\
& P53 M-R & AAA AAA ACG TAA ACG CTT CTC CG & 23 \\
& P53 U-F & GGT TGT TGT ATT TTG GAT TAG ATT TT & 26 & \multirow{2}{*}{170} \\
& P53 U-R & AAA AAA AAC ATA AAC ACT TCT CAC C & 25 & \\
\hline
\end{tabular}

$\mathrm{PCR}=$ polymerase chain reaction; $\mathrm{SNP}=$ single nucleotide polymorphism; $\mathrm{MS}-\mathrm{PCR}=$ methylation-specific $\mathrm{PCR}$.

\section{Polymerase chain reaction-restriction fragment length polymorphism}

PCR was carried out in a final volume of $25 \mu \mathrm{L}$ containing 50 ng genomic DNA template, $1 \mathrm{X}$ PCR buffer with $2 \mathrm{mM} \mathrm{MgCl}, 0.4 \mu \mathrm{M}$ of each primer (Invitrogen), $50 \mu \mathrm{M}$ dNTPs (Amersham Biosciences) and 0.5 U DNA polymerase (Biotools). The PCR cycling conditions were: $94^{\circ} \mathrm{C}$ for $5 \mathrm{~min}$, followed by 35 denaturation cycles of $30 \mathrm{~s}$ at $94^{\circ} \mathrm{C}, 30 \mathrm{~s}$ of annealing at $54^{\circ} \mathrm{C}$, and $30 \mathrm{~s}$ of extension at $72^{\circ} \mathrm{C}$, and a final elongation cycle at $72^{\circ} \mathrm{C}$ for $5 \mathrm{~min}$.

For RFLP, the PCR products were digested by MspI $\left(4 \mathrm{U}\right.$ at $37^{\circ} \mathrm{C}$ for $4 \mathrm{~h}-\mathrm{TP} 53$ Pro47Ser) and $B s t \mathrm{UI}\left(2 \mathrm{U}\right.$ at $60^{\circ} \mathrm{C}$ for $4 \mathrm{~h}$ - TP53 Arg72Pro). $M s p \mathrm{I}$ recognizes a restriction site at Pro47 allele ( $\mathrm{C}^{\mathbf{\nabla}} \mathrm{CGG}$ ) and generates two fragments of different sizes (156 or 140 and 45 bp), while Ser47 allele generates only one fragment of 201 or $185 \mathrm{bp}$ (size divergences due to a 16-bp in/del intronic polymorphism near the TP53 SNP). BstUI generates two fragments of different sizes (52 and $100 \mathrm{bp}$ ) by recognizing a restriction size at $\mathrm{Arg} 72$ allele $\left(\mathrm{CG}^{\mathbf{\nabla}} \mathrm{CG}\right.$ ) and Pro72 allele generates only one (152 bp). DNA fragments were electrophoresed through a $10 \%$ acrylamide:bisacrylamide gel (19:1) and stained with silver nitrate.

PCR products were purified and submitted to bidirectional sequencing, to further confirm the reliability of the genotype analysis. The PCR products were purified with ExoSAP (USB), followed by sequencing with the DYEnamic ET Dye Terminator Kit (Amersham Bioscience), according to instructions. 


\section{Methylation-specific PCR analysis}

Initially, the samples were modified with sodium bisulfite; this treatment of DNA converts all unmethylated cytosines to uracil, leaving the methylated cytosine intact, so that methylated and unmethylated alleles can be differentially amplified with specific primers in PCR. For the bisulfite modification, $2 \mu \mathrm{g}$ DNA was dissolved in $50 \mu \mathrm{L}$ water. Next, $5 \mu \mathrm{L} 3 \mathrm{M}$ $\mathrm{NaOH}$ was added and the mixture incubated at $42^{\circ} \mathrm{C}$ for $20 \mathrm{~min}$. In the next step, $400 \mu \mathrm{L} 3$ $\mathrm{M}$ sodium bisulfite and $30 \mu \mathrm{L} 10 \mathrm{mM}$ hydroquinone were added. The mixture was incubated at $55^{\circ} \mathrm{C}$ in a dark place for $16 \mathrm{~h}$. DNA was purified using Wizard ${ }^{\circledR}$ DNA clean-up System kit (Promega Corporation, USA), following manufacturer recommendations.

PCR were prepared in a final volume of $50 \mu \mathrm{L}$ containing $200 \mu \mathrm{M}$ dNTPs, $1 \mathrm{X}$ PCR buffer with $2 \mathrm{mM} \mathrm{MgCl}, 50 \mathrm{ng}$ modified DNA, $0.4 \mu \mathrm{M}$ of each primer (Invitrogen) and $0.5 \mathrm{U}$ DNA polymerase (Biotools). PCR conditions were: one initial denaturation at $94^{\circ} \mathrm{C}$ for $2 \mathrm{~min}$ and 35 cycles at $94^{\circ} \mathrm{C}$ for $40 \mathrm{~s}, 50^{\circ} \mathrm{C}$ of $1 \mathrm{~min}$ and $72^{\circ} \mathrm{C}$ for $40 \mathrm{~s}$, and a final extension at $72^{\circ} \mathrm{C}$ for 5 min. MS-PCR products were visualized on 8\% acrylamide:bisacrylamide gels (29:1) and stained with silver nitrate. The CpGenome universal methylated DNA (Intergen) was used as methylation control. All experiments were repeated at least twice. The products were visualized on $8 \%$ polyacrylamide gels and stained with silver nitrate. Samples giving signals approximately equivalent to the positive control were designated as methylated. To verify the identity of PCR products, they were purified and sequenced using the DYEnamic ET Dye Terminator Kit (Amersham Bioscience).

\section{Statistical analysis}

PCR-RFLP. The independence of alleles (Hardy-Weinberg equilibrium) was ensured using the chi-square test. The distribution of genotype and allele frequencies among patients and controls was compared using chi-square and Fisher exact tests. Overall survival curves were obtained using the Kaplan-Meier method and compared with a log-rank test. Odds ratio (OR) and 95\% confidence intervals (CI) were calculated using a logistic regression model. Statistical significance was set at $\mathrm{P}<0.05$. Statistical analyses were performed with GraphPad InStat 4.0 and GraphPad Prism 5.0 softwares (GraphPad Software, Inc.).

MS-PCR. Statistical evaluation was performed using the Fisher exact test by the TFPGA software. Differences with P values less than 0.05 were considered to be statistically significant.

\section{RESULTS}

\section{Analysis of tumors and control populations according to the TP53 codon 47 and codon 72 SNPs}

Ninety patients and 100 control subjects were included in this study. The patient sample comprised 54 females and 36 males $(\mathrm{M} / \mathrm{F}$ ratio $=0.65)$ and the control sample consisted of 63 males and 37 females $(\mathrm{M} / \mathrm{F}$ ratio $=1.7)$. Mean age in the patient group was 48 years (range $=1-80$ ) and in the control group was 45 years (range $=18-72$ ). Genotype frequencies in controls and patients were in Hardy-Weinberg equilibrium. Allele and genotype frequencies of 
TP53 Pro47Ser and Arg72Pro in controls and patients are shown in Table 2. The frequencies of Pro/Pro and Pro/Ser among controls were 98 and 2\%, while in patients these were 73.3 and $23.7 \%$, respectively $(\mathrm{P}=0.068)$; Ser47 allele frequency was statistically significant between cases and controls $(0.26$ and 0.01 , respectively, $\mathrm{P}<0.001)$. For TP53 Arg72Pro, Pro72 allele frequency was not statistically significant. Frequencies of the Arg/Arg, Arg/Pro and Pro/Pro genotypes among controls were 48,42 , and $10 \%$, while in patients the frequencies were 22.2 , 53.3, and $24.5(\mathrm{P}=0.826)$.

\begin{tabular}{|c|c|c|c|c|}
\hline SNP & Genotype & Case group & Control group & $\mathrm{P}$ \\
\hline \multirow[t]{3}{*}{ TP53 Pro47Ser } & Pro/Pro & $66(73.3 \%)$ & $98(98 \%)$ & 0.068 \\
\hline & Pro/Ser & $24(26.7 \%)$ & $2(2 \%)$ & \\
\hline & Ser47 allele frequency & 0.26 & 0.01 & $<0.001$ \\
\hline \multirow{4}{*}{ TP53 Arg72Pro } & $\operatorname{Arg} / \operatorname{Arg}$ & $20(22.2 \%)$ & $48(48 \%)$ & 0.826 \\
\hline & Arg/Pro & $48(53.3 \%)$ & $42(42 \%)$ & \\
\hline & Pro/Pro & $22(24.5 \%)$ & $10(10 \%)$ & \\
\hline & Pro 72 allele frequency & 0.5 & 0.31 & 0.385 \\
\hline
\end{tabular}

Data are reported as number with percent in parentheses. $\mathrm{SNP}=$ single nucleotide polymorphism.

Logistic regression analysis for the investigation of polymorphism association with risk of extra-axial brain tumors is presented in Table 3. Compared to Arg/Arg, the most common genotype of the polymorphism TP53 Arg72Pro in the study population, the genotypes with presence of allele Pro revealed an increased risk of tumor development $(\mathrm{OR}=3.23$; $95 \% \mathrm{CI}=1.71-6.08 ; \mathrm{P}=0.003)$. When the polymorphism TP53 Pro47Ser was analyzed, we observed a small increased risk of tumor development for the presence of the allele Ser $(\mathrm{OR}=$ $1.28 ; 95 \% \mathrm{CI}=0.03-2.10 ; \mathrm{P}=0.01)$.

\begin{tabular}{|c|c|c|c|c|}
\hline SNP & Genotype & Case/control & OR $(95 \% \mathrm{CI})$ & $\mathrm{P}$ \\
\hline \multirow[t]{2}{*}{ TP53 Pro47Ser } & Pro/Pro & $66 / 99$ & 1.0 & \\
\hline & Pro/Ser & $24 / 1$ & $1.28(0.03-2.10)$ & 0.01 \\
\hline \multirow[t]{4}{*}{ TP53 Arg72Pro } & Arg/Arg & $20 / 48$ & 1.0 & \\
\hline & Arg/Pro & $48 / 42$ & $3.55(1.82-6.94)$ & 0.03 \\
\hline & Pro/Pro & $22 / 10$ & $2.08(0.85-5.08)$ & 0.005 \\
\hline & Pro/Pro + Arg/Pro & $70 / 52$ & $3.23(1.71-6.08)$ & 0.003 \\
\hline
\end{tabular}

$\mathrm{SNP}=$ single nucleotide polymorphism.

Comparison of overall survival of patients according to TP53 Arg72Pro and Pro47Ser genotypes did not show significant differences $(\mathrm{P}=0.83$ and $\mathrm{P}=0.88$, respectively). In the TP53 Arg72Pro genotype, the median survival of patients with Arg/Arg and Pro/Pro was 43 months and in the Arg/Pro genotype it was 32 months. Survival curves for the TP53 Pro47Ser polymorphism demonstrated that patients with the Pro/Ser genotype lived about 43 months and Pro/Pro genotype 38 months (Figures 1 and 2). 


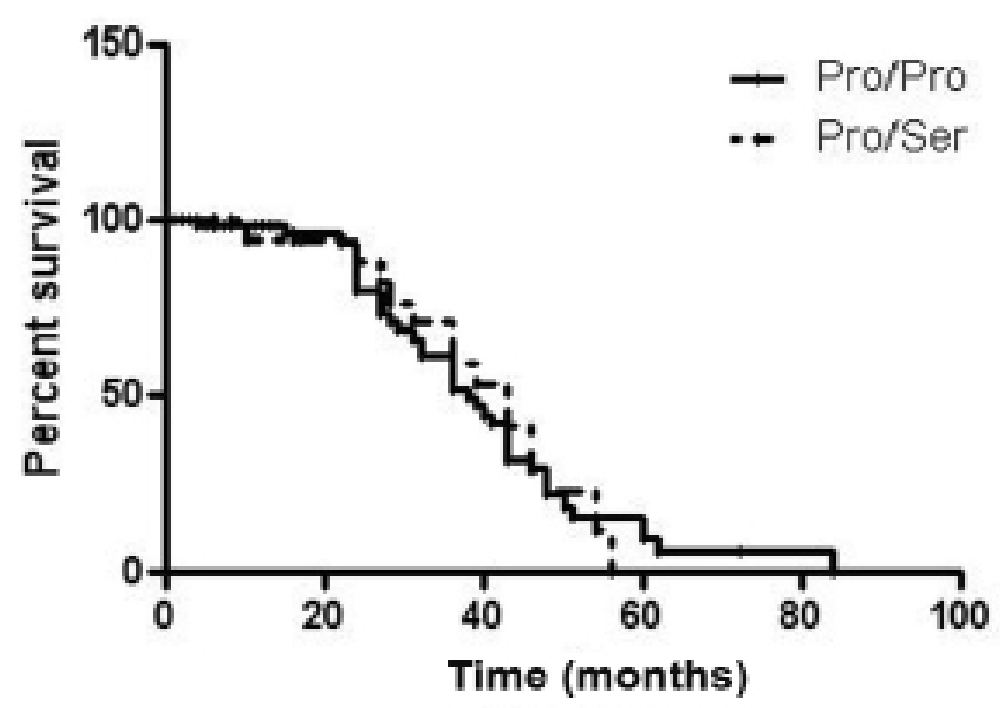

Figure 1. Overall survival in patients according to TP53 Pro47Ser single nucleotide polymorphism.

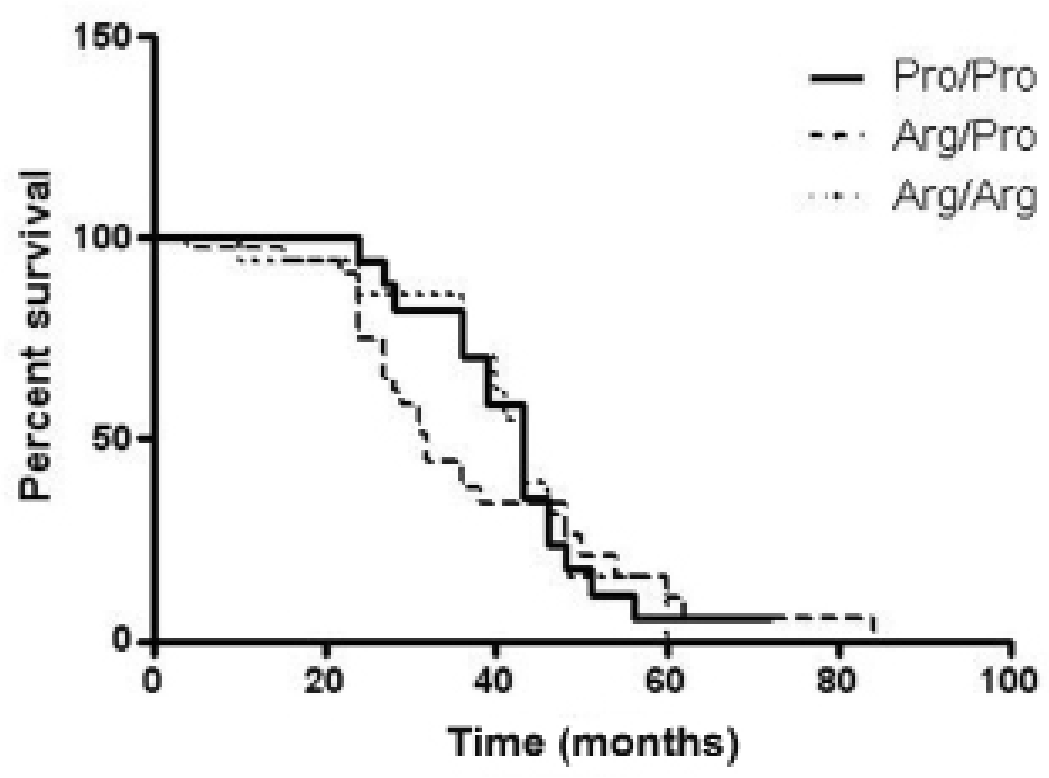

Figure 2. Overall survival in patients according to TP53 Arg72Pro single nucleotide polymorphism. 


\section{Analysis of promoter hypermethylation of P53 gene}

MS-PCR results are presented in Figure 3. We observed that 37.5\% of meningiomas, $30 \%$ of schwannomas and $52.6 \%$ of metastases were hypermethylated. When tumor grade was compared, $35.3 \%$ of benign tumors and $48 \%$ of malignant tumors were methylated. No statistical differences were found between benign and malignant tumors in pattern of methylation $(\mathrm{P}=0.783)$.

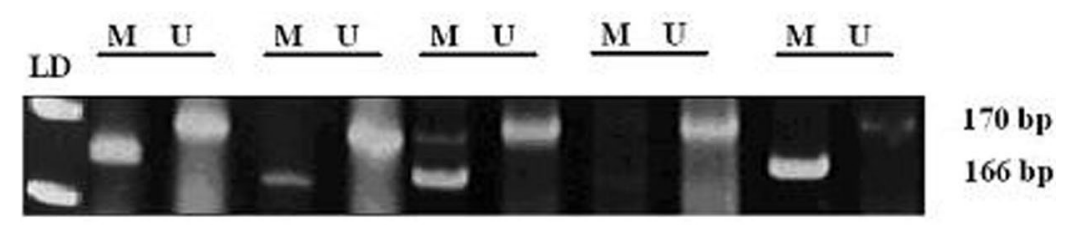

Figure 3. Methylation analysis of TP53 in extra-axial brain tumors. LD: ladder; M: methylated; U: unmethylated.

\section{DISCUSSION}

The concept of neoplastic transformation links together two types of genetic background of cancer with the same final results. Besides entirely somatic cell gene deregulation, a genetically determined susceptibility is taken into account. The predisposition to cancer results from the inheritance of altered alleles of genes, which are usually of the tumor suppressor type. The highly significant tumor suppressor gene, TP53, is implicated in a wide range of human cancers, including brain tumors (Biros et al., 2002). P53 is a multifunctional protein that plays central roles in cellular responses to DNA damage, cellular senescence and apoptosis to maintain genomic stability of a cell (Kashima et al., 2007).

In this study, we determined the promoter hypermethylation status of TP53 gene and the relationship between TP53 Pro47Ser and Arg72Pro SNPs and susceptibility to cancer and patient survival in 90 extra-axial brain tumor samples.

One of the common polymorphisms of the TP53 is codon 72 in exon 4, which changes arginine (CGC) to proline (CCC). Codon 72 polymorphic variants have also been studied as potential susceptible genotypes for several cancers. The functional difference of the TP53 codon 72 polymorphism that has been reported is that the Arg/Arg genotype induces apoptosis with faster kinetics and suppresses transformation more efficiently than the Pro/Pro genotype (Murata et al., 1996; Kuroda et al., 2003). Several groups of investigators have reported an association between the Arg 72 variant and increased risk for gastric, breast, esophagus, skin, lung, and bladder cancers. In contrast, other studies have demonstrated an association between the Pro72 (lower apoptotic activity) variant and increased risk for other cancers including thyroid, prostate and nasopharynx. Other studies did not find any association between TP53 codon 72 polymorphism and cancer (Hadhri-Guiga et al., 2007).

The present case-control study showed that the Pro72 allele was more frequent in the cancer population than in non-cancer populations ( 0.5 and 0.31 , respectively; $\mathrm{P}=0.385)$, and that the presence of this genotype may increase the risk of developing extra-axial brain tumors 
$(\mathrm{OR}=3.23 ; 95 \% \mathrm{CI}=1.71-6.08 ; \mathrm{P}=0.003)$ since the Pro72 variant exhibits a lower ability to induce apoptosis than does Arg72. Biros et al. (2002) analyzed the Arg72Pro polymorphism in meningiomas and astrocytomas, and no significant differences were found with reference to the genotype distribution and haplotype frequencies between cases and controls. Idbaih et al. (2007) studied the influence of the SNP Arg72Pro in the risk of oligodendroglial tumors. They analyzed 275 patients and observed that allele and genotypic frequencies of the codon 72 in controls and patients were very similar, confirming the absence of a relationship between this SNP and oligodendroglial tumors. On the other hand, many studies have found a relationship between Pro72 allele and an increased risk for cancer. Hadhri-Guiga et al. (2007) studied nasopharyngeal carcinomas and observed a significant association between cancer and TP53 codon 72 polymorphism; the Pro/Pro homozygotes are related to a higher risk for development of nasopharyngeal carcinomas. In a study on colorectal cancer, Zhu et al. (2007) found evidence that the Pro 72 variant allele may contribute to the etiology of this tumor; the Pro 72 allele was found more often in patients than in controls $(\mathrm{P}<0.001)$ and carriers of the Pro72 allele had a significantly increased risk of colorectal cancer.

Published research substantially lacks information on TP53 Pro47Ser polymorphism. Felley-Bosco et al. (1993) were the first to report the association of allele Ser with a significantly decreased ability to induce apoptosis. Pinto et al. (2008) investigated the association between the TP53 Pro47Ser and the susceptibility to glioma development and found no association. Our results disagree with the latter study; we observed a significant difference in the frequencies of Ser47 allele between cases and controls $(0.26$ and 0.01 , respectively; $\mathrm{P}<$ $0.001)$ and an increased risk for development of extra-axial brain tumors $(\mathrm{OR}=1.28 ; 95 \% \mathrm{CI}$ $=0.03-2.10 ; \mathrm{P}=0.01)$. The apoptosis process is essential for the maintenance of the equilibrium between cell proliferation and death in tissues in the renovation phase, and resistance to apoptosis is one of the most important characteristics of cancer cells, because it allows their survival and multiplication.

Hypermethylation of the promoter region of a tumor suppressor gene has been increasingly recognized as an alternative mechanism for inactivation of function of a tumor suppressor gene. While the promoter region of TP53 does not contain a classic CpG island, methylation of one or two sites may produce a proportionately greater effect in downregulation of transcription compared to a tumor suppressor gene with a classic $\mathrm{CpG}$ island in the promoter (Sidhu et al., 2005). The methylation of TP53 was reported as a mechanism for its inactivation in some neoplasms, such as acute lymphoblastic leukemia, multiple myeloma, malignant glioma cells, and brain metastases of solid tumors (Lima et al., 2008). Kang et al. (2001) showed TP53 methylation in 3 of 19 (16\%) breast carcinomas. Agirre et al. (2003) observed TP53 methylation in 8 of 25 cases (32\%) of acute lymphoblastic leukemia. Amatya et al. (2004) showed that TP53 methylation is frequent in low-grade gliomas; they observed that $60 \%$ of low-grade astrocytomas, $61 \%$ of oligoastrocytomas and $73 \%$ of oligodendrogliomas were methylated. The present study shows that the methylation of the TP53 gene is an important event associated with extra-axial brain tumors, since $37.5 \%$ of meningiomas, $30 \%$ of schwannomas and $52.6 \%$ of metastases were found to be hypermethylated, and TP53 methylation can be involved in the progression of these tumors, since we observed that $48 \%$ of the malignant tumors were methylated.

In summary, our study provides evidence that TP53 Arg72Pro and Pro47Ser may contribute to the etiology of extra-axial brain tumors, since the alleles Pro72 and Ser47 were 
found more frequently in patients than controls, but there was no association between the genotypes and the patients' survival. We observed that TP53 methylation is an important event for the genesis and progression of these tumors.

\section{ACKNOWLEDGMENTS}

We are grateful to the patients who took part in this investigation. We thank Vanderci Massaro de Oliveira and Marcio Rogério Penha for the technical support provided in this study. Reseach supported by Conselho Nacional de Desenvolvimento Científico e Tecnológico (CNPq), Fundação de Amparo à Pesquisa do Estado de São Paulo (FAPESP) and Fundação de Apoio ao Ensino, Pesquisa e Assistência do Hospital das Clínicas da Faculdade de Medicina de Ribeirão Preto (FAEPA).

\section{REFERENCES}

Agirre X, Vizmanos JL, Calasanz MJ, Garcia-Delgado M, et al. (2003). Methylation of CpG dinucleotides and/or CCWGG motifs at the promoter of TP53 correlates with decreased gene expression in a subset of acute lymphoblastic leukemia patients. Oncogene 22: 1070-1072.

Amatya VJ, Takeshima Y and Inai K (2004). Methylation of p14(ARF) gene in meningiomas and its correlation to the p53 expression and mutation. Mod. Pathol. 17: 705-710.

Bello MJ, Aminoso C, Lopez-Marin I, Arjona D, et al. (2004). DNA methylation of multiple promoter-associated CpG islands in meningiomas: relationship with the allelic status at 1p and 22q. Acta Neuropathol. 108: 413-421.

Biros E, Kalina I, Kohut A, Bogyiova E, et al. (2002). Allelic and haplotype frequencies of the $\mathrm{p} 53$ polymorphisms in brain tumor patients. Physiol. Res. 51: 59-64.

Costa S, Pinto D, Pereira D, Rodrigues H, et al. (2008). Importance of TP53 codon 72 and intron 3 duplication 16bp polymorphisms in prediction of susceptibility on breast cancer. BMC Cancer 8: 32.

Drevelegas A (2005). Extra-axial brain tumors. Eur. Radiol. 15: 453-467.

Esteller M, Corn PG, Baylin SB and Herman JG (2001). A gene hypermethylation profile of human cancer. Cancer Res. 61: 3225-3229.

Felley-Bosco E, Weston A, Cawley HM, Bennett WP, et al. (1993). Functional studies of a germ-line polymorphism at codon 47 within the p53 gene. Am. J. Hum. Genet. 53: 752-759.

Hadhri-Guiga B, Toumi N, Khabir A, Sellami-Boudawara T, et al. (2007). Proline homozygosity in codon 72 of TP53 is a factor of susceptibility to nasopharyngeal carcinoma in Tunisia. Cancer Genet. Cytogenet. 178: 89-93.

Hurt EM, Thomas SB, Peng B and Farrar WL (2006). Reversal of p53 epigenetic silencing in multiple myeloma permits apoptosis by a p53 activator. Cancer Biol. Ther. 5: 1154-1160.

Idbaih A, Boisselier B, Marie Y, El Hallani S, et al. (2007). TP53 codon 72 polymorphism, p53 expression, and 1p/19q status in oligodendroglial tumors. Cancer Genet. Cytogenet. 177: 103-107.

Kang JH, Kim SJ, Noh DY, Park IA, et al. (2001). Methylation in the p53 promoter is a supplementary route to breast carcinogenesis: correlation between $\mathrm{CpG}$ methylation in the $\mathrm{p} 53$ promoter and the mutation of the $\mathrm{p} 53$ gene in the progression from ductal carcinoma in situ to invasive ductal carcinoma. Lab. Invest. 81: 573-579.

Kashima T, Makino K, Soemantri A and Ishida T (2007). TP53 codon 72 polymorphism in 12 populations of insular Southeast Asia and Oceania. J. Hum. Genet. 52: 694-697.

Kuroda Y, Tsukino H, Nakao H, Imai H, et al. (2003). p53 Codon 72 polymorphism and urothelial cancer risk. Cancer Lett. 189: 77-83.

Kuroda Y, Nakao H, Ikemura K and Katoh T (2007). Association between the TP53 codon 72 polymorphism and oral cancer risk and prognosis. Oral Oncol. 43: 1043-1048.

Leite JL, Manfrinatto JA, Mazzali M and Ward LS (2006). Polymorphisms at exon 4 of p53 and the susceptibility to herpesvirus types 6 and 1 infection in renal transplant recipients. Transpl. Int. 19: 732-737.

Leu JI, Dumont P, Hafey M, Murphy ME, et al. (2004). Mitochondrial p53 activates Bak and causes disruption of a BakMcl1 complex. Nat. Cell Biol. 6: 443-450.

Li LC and Dahiya R (2002). MethPrimer: designing primers for methylation PCRs. Bioinformatics 18: 1427-1431.

Li X, Dumont P, Della PA, Shetler C, et al. (2005). The codon 47 polymorphism in p53 is functionally significant. J. Biol. 
Chem. 280: 24245-24251.

Lima EM, Leal MF, Burbano RR, Khayat AS, et al. (2008). Methylation status of ANAPC1, CDKN2A and TP53 promoter genes in individuals with gastric cancer. Braz. J. Med. Biol. Res. 41: 539-543.

Liu Y, Pang JC, Dong S, Mao B, et al. (2005). Aberrant CpG island hypermethylation profile is associated with atypical and anaplastic meningiomas. Hum. Pathol. 36: 416-425.

Murata M, Tagawa M, Kimura M, Kimura H, et al. (1996). Analysis of a germ line polymorphism of the p53 gene in lung cancer patients; discrete results with smoking history. Carcinogenesis 17: 261-264.

Pietsch EC, Humbey O and Murphy ME (2006). Polymorphisms in the p53 pathway. Oncogene 25: 1602-1611.

Pinto GR, Yoshioka FK, Silva RL, Clara CA, et al. (2008). Prognostic value of TP53 Pro47Ser and Arg72Pro single nucleotide polymorphisms and the susceptibility to gliomas in individuals from Southeast Brazil. Genet. Mol. Res. 7: 207-216.

Sidhu S, Martin E, Gicquel C, Melki J, et al. (2005). Mutation and methylation analysis of TP53 in adrenal carcinogenesis. Eur. J. Surg. Oncol. 31: 549-554.

Sprague BL, Trentham-Dietz A, Garcia-Closas M, Newcomb PA, et al. (2007). Genetic variation in TP53 and risk of breast cancer in a population-based case control study. Carcinogenesis 28: 1680-1686.

Zhu ZZ, Wang AZ, Jia HR, Jin XX, et al. (2007). Association of the TP53 codon 72 polymorphism with colorectal cancer in a Chinese population. Jpn. J. Clin. Oncol. 37: 385-390. 